\title{
Ethical and Psychological Factors in 5S and Total Productive Maintenance
}

\author{
Jamal Ahmed Hama Kareem¹ ${ }^{1}$, Othman Abdul-Qader Hama Amin² \\ ${ }^{1}$ Sulaimani University, Kurdistan (Iraq) \\ ${ }^{1,2}$ University of Human Development, Kurdistan (Iraq) \\ ${ }^{2}$ University of Sulaimani Polytechnic, Kurdistan (Iraq) \\ ramanahmed79@yahoo.com, dr.othman2011@.gmail.com
}

Received: April 2017

Accepted: June 2017

\section{Abstract:}

Purpose: The purpose of this paper is to investigate the role of ethical and psychological factors in the implementation of 5S and TPM at cement plants in Kurdistan Region of Iraq.

Design/methodology/approach: The mixed methods represented in a questionnaire survey and semi-structured interviews for data collection in the framework of the case study were chosen. The questionnaire survey already has been tested.

Findings: The findings of this paper revealed that ethical factors had a larger role than psychological factors in the implementation. Thus, based on the findings, organisations are recommended to provide financial and moral support to employees to enable a comprehensive implementation of 5S and TPM aimed at obtaining the desired results.

Originality/value: The current paper tried to introduce a new theoretical contribution by filling the gap in the literature regarding the important role that can be played by ethical and psychological factors of employees in the successful implementation of contemporary techniques, such as $5 \mathrm{~S}$ and TPM in industrial organizations. This is contrary to what was done most of the previous studies such as Ahuja and Khamba (2008b), Panneerselvam (2012), Singh, 
Gohil, Shah and Desai (2013) and Poduval and Pramod (2015) in the area of 5S and TPM. Where, these studies have focused on studying the other factors such as (organizational, technological, operational and others) in implementing 5S and TPM. This without realizing the fact that it is also necessary to examine factors such as (ethical and psychological) that would affect the capabilities and employee morale before and during the implementation of those techniques ( $5 \mathrm{~S}$ and TPM) that are used to bring out the best productivity.

Keywords: ethical and psychological factors, 5S, TPM, Kurdistan, Iraq

\section{Introduction}

5S and Total Productive Maintenance (TPM) are recognized as key concepts in Lean and World Class Manufacturing models. Nevertheless, few organizations understand the benefits that can accrue from their simultaneous implementation (Kennedy \& Mazza, 2010). According to Gapp, Fisher and Kobayashi (2008), many firms and factories have implemented either of these two techniques, without realizing that the $5 \mathrm{~S}$ method is tantamount to foundation stone toward the implementation of the TPM program. Furthermore, researchers highlighted that simultaneous implementation of these two techniques (5S and TPM) is not impossible, and their implementation together in a single system can bring many benefits to the industrial organizations, including a large improvement the safety at the work environment, asset performance, quality, productivity and most importantly financial performance. All these, in turn, will help these organizations to improve the current situation and to strengthen its competitive position by improving the production effectiveness and meeting the needs of customers and consumers as required (Graisa \& Al-Habaibeh, 2011; Gajdzik, 2009; Hegde, Mahesh \& Doss, 2009; Arashpour, Enaghani \& Karimi, 2009).

However, many researchers like Ahuja and Khamba (2008b), Hegde et al., (2009), Arashpour et al., (2009), Graisa and Al-Habaibeh (2011), Moradi, Abdollahzadeh and Vakili (2011), Haddad and Jaaron (2012) and Singh et al., (2013) have confirmed through studies that they conducted on many industrial organizations which implementing these techniques (5S and TPM) that, there are still companies and factories around the world suffer from several of the obstacles and challenges, including organizational, cultural, technological and operational within their productive processes during the implementation of these techniques. Nevertheless, the successful implementation of 5S and TPM depends not only on the diagnosis of the obstacles and challenges that hinder the implementation of these techniques (5S and TPM) to improve the overall production lines effectiveness and attain competitive advantage, but it also depends on the capacities of human resources (employees) that affect the successful implementation of 
5S and TPM in the organization (Wagel, 1990). Thus, the employee is a considered the main and decisive component for successful implementation of $5 \mathrm{~S}$ and TPM and achieving the desired competitive advantage for organizations, this according to what confirmed by researchers (Kennedy \& Mazza, 2010; Kumar, Soni \& Agnihotri, 2014). Therefore, it should be highlighted on this component through a set of ethical and psychological factors and their role in the implementation of the tasks of $5 \mathrm{~S}$ and TPM.

Thus, confirmation of the above statement, Wagel (1990) and Ginder, Robinson and Robinson (1995) indicated that the industrial organizations rely heavily on their workforce to attain the desired levels of performance either in production or in financial. This reliance is largely based on the workforce (employees) capacities, which can be affected by a set of factors. This is because the quality of services provided by industrial organizations is mortgaged to the extent of their employees' adherence to set of ethical factors, such as: i) Manager-subordinate relationship (Autonomy/empowerment); ii) Ethical training programs; iii) The ethical instructions and commands. The other factor, which considered important is the psychological factors, include: i) Motivation and morale; ii) Job security and work load; iii) Awareness and sense of responsibility (Wagel, 1990; Ginder et al., 1995; Ireland \& Dale, 2001; Ramayah, Jantan \& Hassan, 2002; Brah \& Chong, 2004; Seth \& Tripathi, 2005; Gapp et al., 2008; Ahuja \& Khamba, 2008b; Haroun \& Duffuaa, 2009; Panneerselvam, 2012; Rolfsen \& Langeland, 2012; Aspinwall \& Elgharib, 2013; Kumar et al., 2014).

\section{Literature Review}

$5 \mathrm{~S}$ and TPM have been developed for optimal utilization of existing organizational resources (Chan, Lau, Ip, Chan \& Kong, 2005; Gajdzik, 2009) and to benefit from them fully, the organizations need to develop strategies and take into account factors that may hinder in the proper implementation of these two techniques (5S and TPM) (Hegde et al., 2009). These techniques not only affect the production processes but on the organization as a whole. Thus, for their effective implementation the main cornerstone is the employee itself, that needs to take into consideration before any implementation process takes place. Ahuja and Khamba (2008a) also highlighted that a major shift in the psyche and behaviour of employees is required before successful implementation of $5 \mathrm{~S}$ and TPM can take place.

Employees being the main pillar of the implementation process are affected by two kinds of factors: ethical and psychological. These factors are important in changing the attitudes and behaviours of the employees (Wagel, 1990). Researchers like Chan et al. (2005) and Ginder et al. (1995) have highlighted that the successful implementation of modern techniques such as (5S and TPM) by the industrial organizations to improve the production effectiveness and attain the desired competitive advantage 
depends on the capacities of human resources (employees) that, in turn, affected by the set of ethical and psychological factors.

\subsection{S and TPM Implementation}

Van Patten (2006) has highlighted the benefits of using the 5S method. He pointed out that 5S method when applied not only improves the communication between employees, but also helps them acquire skills and capabilities that are useful in reducing downtime, lead time, inventory, defect, injury and associated costs. Researchers suggested that implementation of $5 \mathrm{~S}$ method helps organizations to implement changes, improve their health and safety standards as well as housekeeping (Rahman, Khamis, Zain, Deros \& Mahmood; Esain, Williams \& Massey, 2008; Khamis, Abrahman, Jamaludin, Ismail, Ghani \& Zulkifli, 2009). Similarly, researchers have pointed out that the implementation of 5S method helps organizations to attain competitive position (Kumar, 2007; Karim \& Arif-Uz-Zaman, 2013).

$5 \mathrm{~S}$ is one of the lean manufacturing techniques that is widely accepted and adopted by the industry (Boca, 2011) and its implementation largely depends on the organizational characteristics (Sousa \& Voss, 2008; Bayo-Moriones, Bello-Pintado \& Merino-Díaz de Cerio, 2010). The method not only improves health and safety environment of an organization but also improves and enhances data information system within organizations (Khamis et al., 2009; Ananthanarayanan, 2006). It has been reported that companies that implement the $5 \mathrm{~S}$ method, had a significantly reduced rate of work-related incidents mainly due to safety steps included in the technique that enhances the overall well-being of employees (Ansari \& Modarress, 1997; Da Silveira, 2006; Roziana, 2011). Researchers like Michalska and Szewieczek (2007) pointed out that $5 \mathrm{~S}$ method is the key to productivity and quality, and the adoption of the $5 \mathrm{~S}$ techniques could help in resolving many day to day problems that are encountered by the employees. Therefore, they recommended training employees on how to implement the techniques of $5 \mathrm{~S}$ method to improve working conditions in the organization. Researchers have outlined five levels of $5 \mathrm{~S}$ method implementation like the commitment of the top management, promotional campaign, proper and systematic record keeping and 5S training and evaluation (Ho \& Cicmil, 1996; Warwood \& Knowles, 2004).

Seiichi Nakajima, in his well-known book, TPM Development Program, has pointed out that the TPM program is an innovative Japanese concept. This concept can be traced back to the introduction of preventive maintenance in Japan during the 1950s to support lean manufacturing by using preventive and corrective maintenance (Lemma, 2008). Through preventive maintenance, the useful life of equipment can be prolonged before deterioration causes failure (Cua, Mckone-Sweet \& Schroeder, 2006). In this concept, the machine operator does not handle maintenance of the machine but maintenance staff does 
it. This concept was applied by Nippondenso Co. a supplier of electrical parts to Toyota during the 1960s to handle preventive and automated maintenance and to carry out modifications for improving the reliability of the installed equipment (Suzuki, 1994; Kholopane, 2016). Thus, preventive maintenance along with Maintenance prevention and Maintainability Improvement gave birth to TPM (Venkatesh, 2007), which later on evolved into strategy focusing on total productive maintenance through employee participation (Lemma, 2008).

The TPM program bases itself on the concept of "prevention at source". Through this concept, factors are identified and eliminated before equipment enters into deterioration stage, thus prolonging the useful life of the equipment and at the same time enhancing its productive utilization. Today the concept of TPM is widely accepted and has been implemented in various industries (Eti, Ogaji \& Probert, 2006; Ngugi, 2015).

Research suggested that $5 \mathrm{~S}$ method and total productive maintenance (TPM) can be integrated together (Ahuja \& Khamba, 2008a; Moradi et al., 2011). Hegde et al., (2009) was of the view that there is a need to make $5 \mathrm{~S}$ techniques as a basis stone for the implementation of TPM program, which in turn helped to minimize the breakdowns, increasing performance and quality rate of the machine thus improving the effectiveness of productive equipment. Similarly, Gapp et al. (2008) and Gajdzik, (2009) highlighted that $5 \mathrm{~S}$ and TPM together are key concepts in Lean and World-Class Manufacturing models, where 5S method is the first and basic step of implementation of TPM program, leading improvement in the workplace safety and environment, asset performance, quality, delivery, productivity and most importantly financial performance. While, Sahu, Batham and Bangar (2012) and Attri, Grover Dev and Kumar (2013) considered that, the $5 \mathrm{~S}$ techniques are the first pillar of TPM program pillars. According to them "TPM starts with 5S, problems cannot be clearly seen when the workplace is unorganized. Cleaning and organizing the workplace helps the team to uncover problems. Making problems visible is the first step of improvement".

\subsection{Ethical and Psychological Factors for 5S and TPM Implementation}

The current paper tried to introduce a new theoretical contribution by filling the gap in the literature regarding the important role that can be played by ethical and psychological factors of employees in the proper and successful implementation of 5S and TPM techniques. The following is a discussion of these factors (ethical and psychological) of employees and their role in the implementation of contemporary techniques, such as 5S and TPM in industrial organizations. 


\subsubsection{Ethical Factors}

Ethical factors are the factors that related to the organizational strategies and policies like the managersubordinate relationship in terms of autonomy and empowerment, ethical training programs and ethical instructions and commands. These factors are necessary to study them, because they are directly linked to the performance of employees in the implementation of many modern techniques such as 5S and TPM, therefore these factors can leave a negative or positive impact on the implementation of these techniques in industrial organizations, and are discussed below the set of these factors.

\subsubsection{Manager-Subordinate Relationship (Empowerment/Autonomy)}

For the performance of organizations be successful, both management and employees need to be in harmony by developing an environment of trust and cooperation (Jadhav, Mantha \& Rane, 2014). The improvement process must be recognized as benefiting both the company and the employees. The ultimate responsibility for success or failure in achieving the desired goals rests with the management. Employees can accept the concept of teamwork, cooperation and empowerment if management provides leadership, security of employment and reasonable compensation (Ginder et al., 1995; Ulrich, Zenger \& Smallwood, 2013). Therefore, Jadhav et al. (2014) and Haddad \& Jaaron (2012) highlighted, that the major roadblock in the successful implementation of techniques that lead to improving production effectiveness is the reluctance of management to empower employees. Ahuja \& Khamba (2008b) also shared the same viewpoint that the rigid bureaucratic structures of the organizations are that impedes empowerment of the employees. Furthermore, there are the other researchers were of the view that employees are the major cornerstone in the implementation of many techniques such as 5S, Kaizen, Six Sigma and TPM that could enhance the efficiency of an organization and its competitiveness, and without their involvement in the process of the implementation, would render these techniques ineffective during their implementation (Ahuja \& Khamba, 2008b; Haroun \& Duffuaa, 2009; Rolfsen \& Langeland, 2012).

Thus, all of this means that employee empowerment and involvement in the implementation process are crucial and the management need to understand this fact if they want to reap the benefits of successful implementation of these techniques (5S, Kaizen, Six Sigma and TPM); on the other hand, that the lack of employee involvement in the overall implementation can lead to their either failure or partial implementation them (Suzuki, 1994; Rolfsen, 2014). Therefore, the management commitment and employee receptivity are crucial to achieving success in the implementation of the techniques that will improve the performance of the organization as a whole (Gajdzik, 2009). 


\subsubsection{Ethical Training Programs}

Panneerselvam (2012) highlighted the role of correct training and ethical in the effective functioning of the functional departments of an organization and overall improvements in the results, this is through the provision of correct information and their development. He was of the view that to meet the changing requirements, it is necessary to provide a correct training and necessary to employees. He further stressed that the training requirements of the employees are to be determined and managed by the top management of the organization. Similar views have also been expressed by Ginder et al. (1995) who also highlighted the role of correct training and retraining of employees with a view to the development of their information, thereby the successful implementation of tasks which are needed for this. As highlighted by Panneerselvam (2012) that the implementation of 5S and TPM initiatives in the organization requires extensive training and redevelopment of employees' information for success in the implementation of these techniques and reaping the desired results of them widely.

Therefore, it requires awareness and follow-up in training programs these by officials ethically, this is through determining if the information provided to the trainees are correct and sufficient for the purpose of implementing of tasks assigned to them as required and then achieve the desired results. However, and as confirmed by the (Graham, 1986) that the lack of follow-up in the ethical training programs is the ethical dilemma and core faced by most organizations today. Because if have not taken out, this means the inability of trainees to improve their performance and awareness by the changes; therefore, the trainees will resort to unofficial trails in performing the tasks that will be assigned to them after training. As well as, Hayes and Pisano (1994) noted, that the low of awareness and follow-up in ethical training programs, will lead to negative consequences concrete, most notably: 1) Lack of portability of the development the information of trainees, in terms of informing them all that is new to improve their performance and increase their knowledge of field work. 2) Poor evaluation of the trainees towards acquiring new skills and knowledge in terms of the availability of their abilities to perform the realization in the future, that may be difficult to them perform and need a great know.

Similarly, same viewpoint has been expressed by many researchers that partial or unsuccessful implementation by organizations for any of the techniques such as TPM in their productive processes is caused by employees' resistance, lack of training and ethical education and lack of its follow-up by the officials in the organization (Westphal, Gulati \& Shortell, 1997). This reflects that companies who encounter problems in their implementation programs neglected the development of practices that support such implementations. Thereby, the successful implementation of the techniques that would improve the level of production effectiveness in the organization as a whole is based on the ethical 
training and education programs for employees (Mckone, Schroeder \& Cua, 2001). The purpose behind that is to make employees' develop multi-skills that could help them work more diligently, enthusiastically, independently and responsibly (Venkatesh, 2007; Arashpour et al., 2009; Paropate, Jachak \& Hatwalne, 2011). Therefore, requires officials in organizations of follow-up in the ethical training programs that helps to improve the organizational capabilities by enhancing the problemsolving skills of its employees and enabling learning across various functional areas (Mckone et al., 2001). This helps employees' to identify the root causes of a problem that could help them solve it without delaying and stopping the production (Sahu et al., 2012).

\subsubsection{The Ethical Instructions and Commands}

Sometimes employees are subject to the pressures of work, including pressure from some managers in the organization, that can be represented in the control of the managers on the behaviour and performance of employees, which would have a negative effect on the efficiency of the implementation of several technologies such as 5S, Kaizen, Six Sigma and TPM as employees are asked to do certain tasks that are not according to the training they are provided (Mullins, 2007; Ahuja \& Khamba, 2008b; Kumar et al., 2014). This is, in turn, can lead employees to work under the laws, regulations and instructions issued by some of the officials according to what commensurate with their personal interests in the organization, which in turn makes the employee carry a load cannot avoid or escape from (Wagel, 1990; Idris, 2001). Consequently, employee performance for tasks would be in the unseemly form and unethical, thus reflecting negatively on the success of organizations to achieve the desired goals (Kumar et al., 2014).

Trevino and Nelson (2010) further confirmed about some of the immoral positions in the organization, when some of the employees are subjected to the pressures of the so-called ethical instructions and commands at work. For example, an employee may be asked to purchase items or equipment from manager's quick approval without going into the details of the equipment or item necessary for the organization or not. These positions and others can put the employee in front of difficult choices, which can be exposed either directly or indirectly, and that, in turn, could put the employee under the pressure of the reaction of immediate supervisor, which can cost him stability of his job or profession in the future (Cohen \& Eimicke, 2003).

Therefore, many researchers confirmed, that for the success of organizations in the implementation of techniques for improving the level of productivity and attaining competitive advantage, organizations should: 1) Issue rules and instructions and standardized procedures, and all employees should abide by them literally and ethically during their performance of the tasks entrusted to them. 2) Fight wrong 
behaviors, which can be established by many immoral attitudes in the organization (Ramayah et al, 2002; Seth \& Tripathi, 2005; Haroun \& Duffuaa, 2009; Rolfsen \& Langeland, 2012; Aspinwall \& Elgharib, 2013; Kumar et al., 2014).

\subsubsection{Psychological Factors}

Psychological factors related to employees behavior. For successful implementation of several technologies such as 5S, Kaizen, Six Sigma, and TPM, employees need to be taken into consideration. Without a change in the behaviour of the employees, implementation of these techniques may not be successful. These psychological factors relate to employees morale and motivation, and job security and workload, and also awareness and a sense of responsibility. These factors are briefly discussed below.

\subsubsection{Motivation and Morale}

Kennedy and Mazza (2010) and Gajdzik (2009) were of the opinion that if employees have been sensitized to the benefits of the implementation of the $5 \mathrm{~S}$ techniques, it would not only help in improving the overall working environment by making it safer and more comfortable, but it would also help in improving the motivation and morale of the employees; this, in turn, leads to increased eagerness of employees and their responsibilities towards correct implementation the TPM program pillars (Singh et al., 2013; Haddad \& Jaaron, 2012), thereby improving the level of the overall production through the improvement the production lines effectiveness (OLE) (Nachiappan \& Anantharaman, 2006; Nelson-Raja, Kannan \& Jeyabalan, 2010). This stresses that the top management should provide the necessary financial and moral support for the performance of their tasks to raise the overall motivation of the employees (Pramod, 2007). This also leads to enhanced employee morale and teamwork spirit toward the implementation of the tasks entrusted to them and improvement of the overall level of production effectiveness (Roziana, 2011).

Researchers highlighted that implementation of 5S and TPM within one system would help reduce the workplace inefficiencies that lead to workplace accidents and low employee morale (Gapp et al., 2008; Moulding, 2010; Haddad \& Jaaron, 2012; Ginbey, 2013; Dennis, 2016). According to above narrative by the researchers, the researcher believes that if the top management provided the necessary financial and moral support to employees as well as listen to employees' opinions and suggestions regarding improving the performance of tasks employees would have a stronger sense of ownership and their morale and motivation to successfully implement several techniques, including 5S and TPM, would be raised. 


\subsubsection{Fear of Job Security and Workload}

Nahm, Lauver and Keyes (2012) were of the view that employees perceived job security threat is an important factor in the successful implementation of modern techniques like TPM. However, they further elaborate that the real motive behind the implementation of such techniques is to reduce labour cost and lay off people when such techniques are successful in enhancing productivity and efficiency. Such practices only decrease the level of employees' trust in the management and elicit lower motivation to participate in the implementation process.

Ginder et al. (1995) also highlighted that for successful implementation of tasks of modern techniques like TPM, there has to be an environment of trust between management and employees. Citing the examples of Japan and U.S., they highlighted that in Japan there is a tacit understanding between employees and management, which they call a social contract, through which employees are provided lifetime job guarantee after the implementation of these techniques and in return, employees show loyalty and commitment towards organizational objectives. In the U.S.; however, no such tacit contract exists between management and employees, and employees focus more on their own interest rather than focusing on organizational interest. A similar viewpoint was also highlighted by Nahm et al. (2012) and Bonavia and Marin-Garcia (2011) who found that a direct relationship exists between employees' job security and the successful implementation of the studied implementation of lean processes; this study found a direct relationship between job security, successful implementation and performance.

Panneerselvam (2012), Dhindsa (2012) and Eswaramoorthi, Kathiresan, Prasad and Mohanram (2011) said that organizations also feel resistance from employees. As a result, they perceive that implementation of modern techniques would bring an increased workload as they would be involved in the implementation of relatively new activities addition to current activities and may not be commensurate with the nature of their specialization as well. Jain, Bhatti, Deep and Sharma (2012) highlighted that prolonged working hours may cause fatigue and stress leading to lower motivation and morale of employees to support implementation activities. Panneerselvam's (2012) opinion was that creating an environment of trust between management and employees by changing the organizational culture and providing appropriate training to employees to enhance their skills can lessen anxiety and fear of employees and their resistance towards implementation. Similarly, Kennedy and Mazza (2010) and Ahuja and Khamba (2008b) were of the opinion that to enhance the financial position and competition in organizations successful implementation of many modern techniques like 5S and TPM is required. It is necessary for total employee involvement in the implementation processes by providing training and proper empowerment for them, and also it is necessary for seeking to reduce the concern of employees about "What's in it from the implementation of tasks for me" during implementation of modern techniques, this is by providing the necessary educational programs to 
reduce these concerns for employees. Thus, these organizations can take the full benefit of implementation of employees to these techniques and the lack of their resistance to it (Eswaramoorthi et al., 2011; Poduval \& Pramod, 2015).

\subsubsection{Awareness and Sense of Responsibility}

It has been highlighted by research that when employees are sensitized and their involvement in organizational matters, their performance is not only improved, but also their sense of responsibility it the direction of the tasks performed, thus their implementation of those tasks to the fullest possible (Aspinwall \& Elgharib, 2013). Researchers highlighted that through success the organizations in the implementation of modern techniques like TPM as required, they can change their employees' culture and their perceptions, and they become more aware of these techniques. Employees are also more likely to be involved in their work and show the more responsive attitude towards investigation the desired objectives (Venkatesh, 2007; Ahuja \& Khamba, 2008b). Ginder et al. (1995) highlighted that in cooperative societies like Japan employees and management have an unwritten, social contract that links management and employees' together. In this social contract, employees are provided security related to their jobs, and in turn, employers limit their self-interest for the overall interest of the organization. This helps to develop employee loyalty and responsibility towards organizational benefits and objectives.

Hutchins (2007) also highlighted that the employees should be involved in the implementation process and they should be taken into confidence before any implementation is going to take place. If employees are aware of the processes and have been taken into confidence, they would show a responsible attitude towards the implementation of these processes, which would help achieve the implementation of objectives as well. A similar viewpoint was also expressed by Ahuja and Khamba (2008b), Kumar et al. (2014) and Eswaramoorthi et al. (2011) that if employees are provided with detailed knowledge and training regarding many techniques such as (5S and TPM), and are made aware of the benefits they can bring to themselves as well as to the company, the employees will put in more effort and time to make the implementation of these techniques a success. Finally, Gapp et al. (2008) suggested that successful implementation of 5S and TPM would require continuous organizational resolve for their implementation. Moreover, it was also suggested by the researchers that shortcuts and unrealistic schedule plans for their implementation may result in failure and subsequent decline in the motivation of employees. Organizations need to continue their implementation of these two methods no matter how long it takes; the focus should always be to learn from mistakes for better efforts (Kennedy \& Mazza, 2010). 


\section{Study Model and Hypothesis Development}

The study objective is to show better understand the real role which the ethical and psychological factors could be played in the implementation of 5S and TPM and difference in the levels of their implementation in the field of the cement industry, which has not been studied in any previous researchers. Based on foregoing, the study model has been built along with the hypotheses of the study; this is for verification of the goal of the present study.

\subsection{Study Model}

The purpose of this model was to fill the gap in the literature regarding the important role that can be played by employees' ethical and psychological factors in the implementation of 5S and TPM and difference in the levels of their implementation in the cement factories under study. The model is shown in Figure 1.

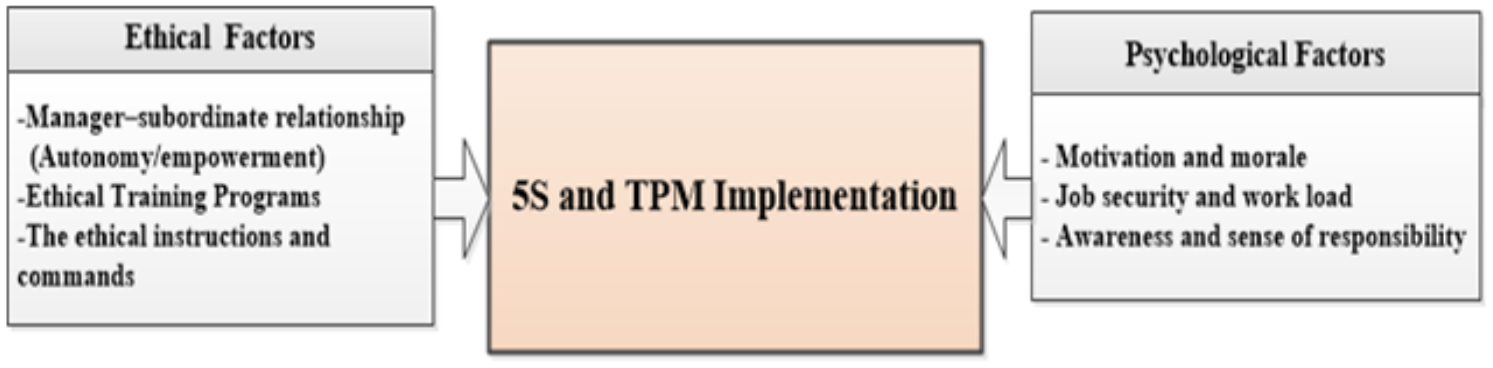

Figure 1. Study model

\subsection{Hypothesis Development}

Based on the study model above and by depending on the literature review in the current study, the following hypotheses were drafted. This is for the purpose of the investigation of the role of employees' ethical and psychological factors in the implementation of 5S and TPM and difference in the levels of their implementation.

Hypothesis 1: Ethical factors would have a strong role in the implementation of 55 and TPM.

Hypothesis 2: Psychological Factors would have a strong role in the implementation of $5 S$ and TPM.

Hypothesis 3: Ethical factors would have a bigger role in $5 S$ and TPM implementation than psychological factors. 


\section{Methodology of Study}

The current study is descriptive in nature, which aiming to explore the real role could be played by ethical and psychological factors in the implementation of 5S and TPM and difference in the levels of their implementation. In the study, the cement sector organizations in Kurdistan region/Iraq were selected to be as the study sample. This sample was selected on the basis of the stratified sampling technique. Table 1 highlights stratified random sampling and corresponding sample based on random sampling technique.

\begin{tabular}{|c|r|r|r|}
\hline Strata & \multicolumn{1}{|c|}{ Population } & $\begin{array}{c}\text { Percentage } \\
\text { of population }\end{array}$ & \multicolumn{2}{c|}{$\begin{array}{c}\text { Proportional } \\
\text { sample }\end{array}$} \\
\hline Tasluja & 1512 & 38 & 135 \\
\hline Bazian & 928 & 23 & 81 \\
\hline Mass & 1561 & 39 & 138 \\
\hline Total & 4001 & 100 & 354 \\
\hline
\end{tabular}

Table 1. Stratified population and sample

As the sample size for a population of 4001, 354 come out according to Krejcie and Morgan (1970). Thus, based on strata and proportional representation condition of stratified sampling, the sample for each cement factory was Tasluja (135), Bazian (81) and Mass (138). Worth mentioning that the human resources departments of the three organizations are that supplied to the researcher the number of the participants (Population). These participants were included of various grades.

Research design helps the researcher to operationalize variables, collect and analyse data and find a solution to the problem of research (Becker, Bryman \& Ferguson, 2012). As noted earlier, the current study aimed to explore and understand the roles of ethical and psychological factors in the implementation of the 5S and the TPM in cement factories (Tasluja, Bazian and Mass) in Kurdistan Region of Iraq. Therefore, a mix method approach using both quantitative and qualitative methods (survey questionnaire and interviews concurrently) to collect data within the case study framework was selected, which would help in making the results more valid and reliable. Pilot testing was conducted to check the validity and reliability of the survey questionnaire.

A survey methodology was adopted and a self-administered survey questionnaire was designed. The questionnaire composed of three sections. The first section was regard to the ethical and psychological factors. Ethical factors consisted of manager-subordinate relationship, ethical training programs and ethical instructions and commands. These three dimensions were measured using nine items (three items 
to each dimension respectively). The items were taken from the studies of Graham (1986), Ireland and Dale (2001), Brah and Chong (2004), Ahuja and Khamba (2008b), Aspinwall and Elgharib (2013), Haroun and Duffua (2009), Wagel (1990), Idris (2001) and Cohen and Eimicke (2003). These items were measured on a 5-point Likert scale using level of agreement or disagreement. While, the psychological factors consisted of motivation and morale, fear of job security and work load, and awareness and sense of responsibility. These dimensions measured the employees' perceptions regarding the implementation of $5 \mathrm{~S}$ and TPM in their factories. These dimensions were measured using nine items (three items for each dimension) taken from the studies of Ahuja and Khamba (2008b), Aspinwall and Elgharib (2013), Ramayah et al. (2002), Gapp et al. (2008), Eswaramoorthi et al. (2011), Nahm et al. (2012), Panneerselvam (2012) and Dhindsa (2012). All these items were rated on a 5-point Likert scale using level of agreement or disagreement.

The second section of this survey instrument composed of nine items measuring implementation of $5 \mathrm{~S}$ and TPM in terms of the effectiveness of the productive performance of the plant, the safety of the work environment, easy access to the necessary tools and the unification of procedures and training. These items measured the employees' perceptions pertaining the implementation of $5 \mathrm{~S}$ and TPM in their factories. These dimensions were taken from the studies of Ahuja and Khamba (2008b), Gapp et al. (2008), Gajdzik (2009), Graisa and Al-Habaibeh (2011) and Aspinwall and Elgharib (2013). The items were also rated on a 5-point Likert scale using level of agreement or disagreement. The third section of this survey instrument comprised the demographic details of the respondents like gender, work experience, education level, position in the factory and department.

The data collected was analyzed using factor analysis for validity and reliability. Thus, the reliability and validity were verified, Pearson correlation was identified to find out the association of the study variables. For verification the impact, the regression analysis was done. Before applying the regression analysis, the assumptions pertaining to regression were convinced and satisfied. The instrument reliability was found to be 0.832 (ethical Factors) and 0.770 (psychological factors), and the implementation of 5S and TPM was 0.787 . The reliability by using Cronbach's alpha indicated that the instrument was reliable, where all the alpha values were found to be above 0.70 . Factor analysis indicated that the instrument was valid, where all the items were found to have more than 0.40 factor loadings and were retained. The rationale for using this scaled survey questionnaire was to capture the employees' perceptions in terms of both ethical and psychological factors and their role in the implementation of $5 \mathrm{~S}$ and TPM.

Earlier, the survey questionnaires were distributed through the human resource department of each selected factory. For final data collection, permission was taken from each of the respective factories through personal visitations. The managers of the human resources departments of the three factories 
facilitated the survey data collection and also helped the researcher carry out observations of the production lines. Survey questionnaires were distributed to the sample of 354 respondents using proportional sampling method under stratified sampling technique. The questionnaires collected reached to 270; however, the 31 questionnaires were not properly filled, thereby they were discarded. Thus, the final sample that was taken into consideration for data analysis was 239, indicating a response rate of $67.5 \%$. The response of each plant is provided in Table 2 .

\begin{tabular}{|c|c|r|r|r|r|r|}
\hline Sr. & Factory & Distributed & Collected & Discarded & Actual sample collected & Response rate \\
\hline 1 & Tasluja & 133 & 98 & 17 & 81 & $61 \%$ \\
\hline 2 & Bazian & 84 & 61 & 6 & 55 & $65.5 \%$ \\
\hline 3 & Mass & 137 & 111 & 8 & 103 & $75 \%$ \\
\hline \multicolumn{2}{|c|}{ Total } & 354 & 270 & 31 & 239 & $67.5 \%$ \\
\hline
\end{tabular}

Table 2. Sample Response from Selected factories

Furthermore, the semi-structured interviews along with the survey questionnaire were conducted in the current study for the purpose of giving a clearer understanding of the role of the ethical and psychological factors in the implementation of 5S and TPM in the three cement plants. These interviews helped the researcher to have an in-depth knowledge and information about 5S and TPM and their implementation, as well as the role that could be played the ethical and psychological factors in the implementation of these techniques in the selected cement factories. The researcher focused on the middle management of the three departments (Production, Maintenance, and Human resources) of the selected cement factories. The respondents for semi-structured interviews were selected through purposive sampling technique. The criteria chosen for selecting the interview respondents in the cement plants under study was as follows:

- Position as a head of a department in factory

- The information, knowledge and experience regarding the implementation of 5S and TPM

- The authority and powers in decision making at the departmental level

- Directly involved in the implementation of $5 \mathrm{~S}$ and TPM

Thus, all the interviewees' voices were recorded and transcriptions were made for the identification of themes. The transcriptions were also shown to the respondents to verify them and also if they wanted to either add or delete something from the transcription. All of the respondents agreed to transcriptions. This step was necessary as it validated the interview process and transcriptions. 


\section{Results and Discussion}

The present section highlights the results of the survey questionnaire and the statistical techniques which were used to test the hypotheses, along with the findings of semi-structured interviews. It is worth mentioning that the semi-structured interviews were analysed using content analysis approach. This is to get more knowledge and in-depth information about the influence that could be played the ethical and psychological factors in the implementation of $5 \mathrm{~S}$ and TPM in the three cement factories.

\subsection{Profile of Respondents}

This section displays a brief account of the respondents' profiles. The simple frequency counts were used to distribute the respondents according to the following demographic characteristics: gender, age, fieldwork experience and education level. Profile of respondents is shown in Table 3.

\begin{tabular}{|c|c|c|c|c|c|c|c|}
\hline \multicolumn{8}{|c|}{ Respondents background } \\
\hline \multicolumn{2}{|c|}{ Gender } & \multicolumn{2}{|c|}{ Age } & \multicolumn{2}{|c|}{ Field work experience } & \multicolumn{2}{|c|}{ Education level } \\
\hline Items & $\mathbf{N}(\%)$ & Items & $\mathbf{N}(\%)$ & Items & $\mathbf{N}(\%)$ & Items & $\mathbf{N}(\%)$ \\
\hline Male & $160(66.9)$ & Under 25 years & $63(26.4)$ & $<5$ years & $61(25.5)$ & High school graduate & $24(10.0)$ \\
\hline \multirow{3}{*}{ Female } & \multirow{3}{*}{$79(33.1)$} & 25-34 years & $84(35.1)$ & $5-10$ years & $89(37.2)$ & Diploma degree & $63(26.4)$ \\
\hline & & $35-45$ years & $68(28.5)$ & $11-15$ years & $50(20.9)$ & Bachelor degree & $141(59.0)$ \\
\hline & & Over 45 years & $24(10.0)$ & $>15$ years & $39(16.3)$ & Advanced degree & $11(4.6)$ \\
\hline
\end{tabular}

Table 3. Respondents background $(\mathrm{N}=239)$

Through the Table 3:

I. Regarding the gender, the table shows that the employees' percentage of males and females reached $66.9 \%$ and $33.1 \%$, respectively. This distribution is a realistic reflection of the reality of employees in most service and industrial sectors in Kurdistan region/Iraq.

II. As for Age, the above table reveals that the participants aged less than 25 years, between 25 and 34 years, 35 and 45 years, and 45+ years reached (26.4\%), (35.1\%), (28.5\%) and $(10.0 \%)$ respectively. Hence, these percentages show that most of the individuals participating in the survey were young people who enjoy vitality and good response for contemporary techniques such as $5 \mathrm{~S}$ and TPM and their implementation.

III. Field work experience displays that the most of the respondents were employed in their current organizations for more than 5 years but less than 10 years $(37.2 \%)$, followed by less than 5 years 
(25.5\%), between 11 and 15 years (20.9\%), and more than 15 years' experience (16.3\%). These findings show that majority of the respondents have had good work experience in the field of implementation of the new techniques such as 5S and TPM, and are thereby able to show their ability and reap the desired results from the implementation of these techniques, including a large improvement the safety at the work environment, asset performance, quality, productivity and most importantly financial performance.

IV. Education level, as declared in the above table, points that most of the employees held a bachelor's degree $(59.0 \%)$, diploma degree $(26.4 \%)$, were high school graduates $(10.0 \%)$, and advanced degree of the education level (4.6\%). These results indicate that majority of the employees have a good level of education, in addition to what has been confirmed in paragraph (ii) above that most of them are young people. Hence, this means they have the ability to generate all that is good and new by way of ideas and meaningful programs that make of implementation of $5 \mathrm{~S}$ and TPM problem-free in their factories.

\subsection{Descriptive Statistics for Variables}

Descriptive statistics were computed for the variables of the study. Variables were computed from the items using SPSS version 21 and mean, minimum, maximum, standard deviations were calculated for the three major variables. Descriptive statistics have been reported for the variables of the study in Table 4. The minimum and maximum values indicate that the data is within the range of scale confirming the correctness of data. The mean value indicates the respondents' responses, which indicate that all the three variables of the study have received the favourable response from the respondents.

\begin{tabular}{|c|r|r|r|r|}
\hline Variable & \multicolumn{1}{|c|}{ Minimum } & Maximum & Mean & Std. Deviation \\
\hline Ethical factors & 1.67 & 4.44 & 3.0544 & .58723 \\
\hline Psychological factors & 1.89 & 4.44 & 3.0294 & .47626 \\
\hline Implementation of 5S and TPM & 2.33 & 4.56 & 3.3966 & .43588 \\
\hline $\mathrm{N}$ & 239 & & & \\
\hline
\end{tabular}

Table 4. Descriptive statistics for variables of study 


\subsection{Pearson Correlation Analysis for Variables}

Pearson Correlation was carried out to build the association between ethical, psychological factors and the implementation of 5S and TPM. Pearson correlation examines the significant association between variables (Sekaran \& Bougie, 2016). The correlation findings were pointed out in Table 5.

\begin{tabular}{|c|c|c|c|}
\hline & Psychological Factors & Ethical Factors & $\begin{array}{c}\text { Implementation of } 5 S \\
\text { and TPM }\end{array}$ \\
\hline Psychological factors & 1 & & \\
\hline Ethical factors & $.545^{* *}$ & 1 & \\
\hline Implementation of $5 \mathrm{~S}$ and TPM & $.466^{* *}$ & $.518^{* *}$ & 1 \\
\hline
\end{tabular}

${ }^{* *}$ Correlation is significant at the 0.01 level (2-tailed).

Table 5. Correlation matrix for variables of study

Based on Table 5, the findings of Pearson correlation showed that ethical factors had a significant positive and strong relationship with implementation of $5 \mathrm{~S}$ and TPM $(\mathrm{R}=.518, \mathrm{p}<0.01)$. As well as, the findings of Pearson correlation stated that the psychological factors have a moderately strong and positive association with the implementation of $5 \mathrm{~S}$ and TPM $(\mathrm{R}=.466, \mathrm{p}<0.01)$. The psychological factors were found to have a strong positive association with the ethical factors $(\mathrm{R}=.545, \mathrm{p}<0.01)$. Consequently, the Pearson correlation findings point that all the variables are associated with each other. Once association was established between variables, the regression analysis by using linear and multiple regression techniques was conducted. The findings have emerged in the following tables.

\subsection{Regression Analysis}

In the current study, two types of regression analysis were performed. To check the influence of ethical factors on the implementation of $5 \mathrm{~S}$ and TPM, and psychological factors on the implementation of $5 \mathrm{~S}$ and TPM, simple linear regression was used. Multiple regression analysis has been performed for the dimensions of ethical and psychological factors with the dependent variable of implementation of $5 \mathrm{~S}$ and TPM. Furthermore, multiple regression analysis was performed for both ethical and psychological factors with the dependent variable of implementation of $5 \mathrm{~S}$ and TPM. 


\subsubsection{Regression Analysis for Ethical Factors and Implementation of $5 \mathrm{~S}$ and TPM}

Simple linear regression has been used to test the influence of composite variable of ethical factors on the implementation of $5 \mathrm{~S}$ and TPM. This was done to test the first hypothesis which is (Hypothesis 1: Ethical factors would have a strong role in the implementation of $5 \mathrm{~S}$ and TPM). As well as, the multiple regression analysis was performed for three dimensions of ethical factors and implementation of $5 \mathrm{~S}$ and TPM. The regression has been performed to make sure which factor is most influential in the implementation of 5S and TPM in the three factories under study. Tables 6 and 7 reveal the results of the linear and the multiple regression analysis respectively.

\begin{tabular}{|c|r|r|r|r|r|r|r|r|}
\hline Model & \multicolumn{1}{c|}{$\mathbf{R}$} & \multicolumn{1}{c|}{$\mathbf{R}^{2}$} & Adj. $\mathbf{R}^{2}$ & \multicolumn{1}{c|}{ F } & \multicolumn{1}{c|}{ Sig. } & Beta & t & Sig. \\
\hline & .518 & .269 & .266 & 87.046 & 0.000 & & & \\
\hline Ethical factors & & & & & & .385 & 9.330 & .000 \\
\hline
\end{tabular}

Table 6. Linear regression model for ethical factors- implementation of 5S and TPM

The linear regression findings of this study indicate that ethical factors play an important role in the successful implementation of the $5 \mathrm{~S}$ and TPM. The findings refer that the ethical factors as an independent variable have a strong relationship $(\mathrm{R}=0.518)$ with the dependent variable of the implementation of 5S and TPM. The results indicate that the value of R Square here is 0.269 . This means that ethical factors are causing $26.9 \%$ variation in the implementation of $5 \mathrm{~S}$ and TPM. Likewise, the results indicate that the ethical factors have a significant influence $(\beta=0.385, \mathrm{p}<0.05)$ on the implementation of the 5S and TPM. This finding refers that the ethical factors alone will have an influence of $38.5 \%$ on the implementation of $5 \mathrm{~S}$ and TPM.

The semi-structured interviews revealed that all respondents stated that the ethical factors have a clear role in the implementation of 5S and TPM and the occurrence of a difference in the levels of implementation of 5S and TPM. For example, one of the respondents stated that "These factors have a direct impact on the level of performance of employees involved in the implementation of the tasks of $5 S$ and TPM. But the severity of the impact of these factors on the performance of employees varies from one employee to another, which leads to the occurrence of a difference in the levels of implementing the tasks of $5 S$ and TPM in the factory". 


\begin{tabular}{|c|r|r|r|r|r|r|r|r|}
\hline Model & \multicolumn{1}{c|}{$\mathbf{R}$} & \multicolumn{1}{c|}{$\mathbf{R}^{2}$} & \multicolumn{1}{c|}{ Adj. $\mathbf{R}^{2}$} & \multicolumn{1}{c|}{$\mathbf{F}$} & \multicolumn{1}{c|}{ Sig. } & Beta & t & Sig. \\
\hline & .526 & .276 & .267 & 29.932 & .000 & & & \\
\hline Manager-subordinate relationship & & & & & & .062 & 1.332 & .184 \\
\hline Ethical training program & & & & & & .152 & 4.576 & .000 \\
\hline Ethical instructions and commands & & & & & & .162 & 3.531 & .000 \\
\hline
\end{tabular}

Table 7. Multiple simultaneous regression analysis for dimensions of ethical factors- implementation of 5S and TPM

The multiple regression findings of the current study refer that the dimensions of ethical factors are also having a significant role in the implementation of $5 \mathrm{~S}$ and TPM. For instance, the finding refers that the ethical training program $(\beta=0.152, \mathrm{p}<0.05)$ and ethical instructions and commands $(\beta=0.162$, $\mathrm{p}<0.05)$ would have a significant impact. It means that training programs that not only increase the knowledge base of employees, but also increases their capacities to implement $5 \mathrm{~S}$ and TPM would have an influence of $15.2 \%$ on the implementation. Similarly, if employees are given instructions and commands within the rules and regulations of the organizations and they adhere to those instructions and commands they would have an influence of $16.2 \%$ on the implementation of $5 \mathrm{~S}$ and TPM.

However, the manager-subordinate relationship is found to have the insignificant relationship with the implementation. This is mainly due to the fact that employees are not provided with enough freedom and autonomy by the supervisors to work independently to implement 5S and TPM tasks. The semistructured interviews reveal that the respondents feel there are no issues regarding a manager-subordinate relationship. For example, all respondents in Bazian cement plant shared their views that there exists a good relationship between managers and subordinates as managers regularly hold meetings with their subordinates and discuss issues that concern employees and try to solve them.

Nevertheless, the manager-subordinate relationship is found troublesome in Tasluja factory, where all respondents were of the opinion that problems exist with the relationship because Tasluja is a government owned and operated factory and employees resist instructions and commands especially when something new has to be started or implemented. Similarly, the relationship between manager and subordinate was also found not in required level in Mass factory, where the two of respondents in this factory were expressed about the existence of problems in this relationship. The manager often faces resistance from subordinates, especially when he asks them to implement the tasks for modern techniques, such as TPM and 5S because they feel unsure about the proper implementation.

These results are also supported by previous studies such as those of Ginder et al. (1995), Haddad and Jaaron (2012) and Ahuja and Khamba (2008b) which have highlighted that the major challenge in a successful implementation is the reluctance of management to empower employees. Rigid bureaucratic structures that are followed by the majority of the developing countries organizations is the biggest 
hurdle in empowering employees (Ahuja \& Khamba, 2008b). Researchers further highlighted that for successful implementation of modern techniques such as $5 \mathrm{~S}$ and TPM, it is a must that employees are given autonomy and are involved in the implementation (Haroun \& Duffuaa, 2009; Rolfsen \& Langeland, 2012).

Similarly, Pannerselvam (2012) and Ginder et al. (1995) were of the view that provision of correct training and information to employees is necessary for successful implementation. Further, Graham (1986), Hayes and Pisano (1994) and Westphal et al. (1997) have highlighted that low awareness and lack of follow-up training programs can lead to negative consequences for the organizations implementing modern techniques, such as (5S and TPM). Thus, the ethical training programs are necessary for the overall production effectiveness through proper implementation of these techniques (Mckone et al., 2001). Training is necessary as it not only builds the capacity and skills of the employees to work independently (Venkatesh, 2007; Arashpour et al., 2009; Paropate et al., 2011), but also helps them identify the root cause of the problems and solve them in time (Sahu et al., 2012). Likewise, researchers have highlighted that providing ethical instructions and commands that are according to the set rules and regulations of the organization would help in the timely implementation of techniques (Ramayah et al., 2002; Seth \& Tripathi, 2005; Haroun \& Duffuaa, 2009; Rolfsen \& Langeland, 2012; Aspinwall \& Elgharib, 2013; Kumar et al., 2014).

Thus, the regression analysis for the model of ethical factors - implementation of 5S and TPM points that its findings support the first hypothesis; therefore, this hypothesis was accepted.

Hypothesis 1: Ethical factors would have a strong role in the implementation of 55 and TPM.

\subsubsection{Regression Analysis for Psychological Factors and Implementation of $5 \mathrm{~S}$ and TPM}

Simple linear regression has been used to test the influence of composite variable of psychological factors on the implementation of 5S and TPM. This was done to test the second hypothesis that is (Hypothesis 2: Psychological Factors would have a strong role in the implementation of 5S and TPM). As well as, the multiple regression analysis was performed for three dimensions of psychological factors and implementation of $5 \mathrm{~S}$ and TPM. This regression was performed to ascertain which factor is most influential in the implementation of 5S and TPM in the three cement factories. Tables 8 and 9 display the results of the linear and the multiple regression analysis respectively. 


\begin{tabular}{|c|r|r|r|r|r|r|r|r|}
\hline Model & \multicolumn{1}{c|}{$\mathbf{R}$} & \multicolumn{1}{c|}{$\mathbf{R}^{2}$} & Adj. $\mathbf{R}^{2}$ & F & Sig. & Beta & t & Sig. \\
\hline & .466 & .217 & .213 & 65.298 & 0.000 & & & \\
\hline Psychological factors & & & & & & .425 & 8.081 & .000 \\
\hline
\end{tabular}

Predictors: (Constant), psychological factors.

Dependent variable: Implementation of 5S and TPM.

Table 8. Linear regression model for psychological factors- implementation of $5 \mathrm{~S}$ and TPM

The linear regression findings of this study refer that the psychological factors play a significant role in the implementation of $5 \mathrm{~S}$ and TPM. The findings point that psychological factors have a significant impact $(\beta=0.425, \mathrm{p}<0.05)$ and relationship $(\mathrm{R}=0.466)$. It means that psychological factor alone is having an influence of $42.5 \%$ on the implementation of $5 \mathrm{~S}$ and TPM. Likewise, the results indicate that the value of $\mathrm{R}$ Square here is 0.217 . This means that psychological factors are causing $21.7 \%$ variation in the implementation of 5S and TPM. The semi-structured interviews also revealed that through the respondents' opinions, these factors have been termed as important and affect in proper implementation for several of the phases of $5 \mathrm{~S}$ and TPM implementation in the factory.

\begin{tabular}{|c|r|r|r|r|r|r|r|r|}
\hline Model & \multicolumn{1}{|c|}{$\mathbf{R}$} & \multicolumn{1}{c|}{$\mathbf{R}^{2}$} & \multicolumn{1}{c|}{ Adj. $\mathbf{R}^{2}$} & \multicolumn{1}{c|}{$\mathbf{F}$} & \multicolumn{1}{c|}{ Sig. } & Beta & t & Sig. \\
\hline Motivation and morale & .494 & .244 & .234 & 25.157 & .000 & & & \\
\hline Fear of job security and workload & & & & & & .254 & 5.316 & .000 \\
\hline Awareness and responsibility & & & & & & .113 & 2.385 & .018 \\
\hline
\end{tabular}

Predictors: (Constant) motivation and morale, fear of job security and workload, awareness and responsibility. Dependent variable: Implementation of 5S and TPM.

Table 9. Multiple simultaneous regression analysis for dimensions of psychological factors- implementation of 5S and TPM

The multiple regression results related to dimensions of psychological factor indicate that motivation and morale $(\beta=0.254, \mathrm{p}<0.05)$ and fear of job security and workload $(\beta=0.113, \mathrm{p}<0.05)$ are having considerable influence on the implementation; however, awareness and responsibility is found to have insignificant influence on the implementation. This shows that the majority of employees are neither sufficiently aware nor fully responsible for implementation of 5S and TPM.

When the findings regarding the dimensions of psychological factor were triangulated with the interview findings, especially related to awareness and responsibility, one of the respondents in Tasluja cement plant revealed that, it was a buge problem, because our employees did not have sufficient knowledge about these techniques $(5 \mathrm{~S}$ and TPM) and what they will bring to them. Thus, they did not have sufficient sense of responsibility towards the implementation of these techniques. Similarly, another respondent in Tasluja cement plant indicated that, we 
found that employees were not sufficiently aware of these techniques (5S and TPM) and the benefit from their implementation. Thus, we had a huge problem on our hands when we started implementing. Likewise, one of the respondents in Mass cement plant was of the opinion that, we faced a little problem initially as some of the employees were not aware of the benefits of implementation of $5 S$ and TPM, otherwise the majority of the employees knew of $5 S$ and TPM. But, this awareness and cognition were not at the required level which we wanted. Thus, the interview results indicate that awareness and responsibility are of major concern while implementing $5 \mathrm{~S}$ and TPM. However, most interviews indicate that though awareness and sense of responsibility regarding these techniques were present, it was not at the level required by the management.

Furthermore, for the successful implementation of techniques like $5 \mathrm{~S}$ and TPM, it is crucial that management and employees should be in a harmonious relationship by developing an environment of trust and cooperation and that both should realize that the implementation would yield benefits for both the employees as well as the organization (Ginder et al., 1995; Gapp et al., 2008; Ahuja \& Khamba, 2008b; Kumar et al., 2014). This harmonious relationship can be achieved if organizations try to incorporate employees' concerns, before and during the process of implementation.

Previous studies such as Gajdzik (2009), Haddad and Jaaron (2012) and Singh et al. (2013) highlighted that if employees are sensitized to the benefits of the implementation of the $5 \mathrm{~S}$ techniques, it would not only help in improving the overall working environment but would also help in improving the motivation and morale of the employees toward the proper implementation of TPM tasks. The role of top management is crucial in the implementation process through clearly communicating and providing necessary support financially and morally to the employees to improve their skills and abilities which are essential for successful implementation of the tasks entrusted to them (Roziana, 2011; Pramod, 2007). Similarly, researchers have found that sensitizing and educating employees not only enhances awareness among employees, but employees also feel more responsible towards their organization (Aspinwall \& Elgharib, 2013; Venkatesh, 2007; Ahuja \& Khamba, 2008b). As well as, Nahm et al. (2012) and Bonavia and Marin-Garcia (2011) in their studies have found a direct and effective relationship between employees' job security and the successful implementation of 5S and TPM. However, the researchers have found that employees' perception of increased workload can lead to the partial implementation of 5S and TPM (Panneerselvam, 2012; Ahuja \& Khamba, 2008b; Eswaramoorthi et al., 2011). Jain et al. (2012) have also highlighted that prolonged working hours may cause fatigue and stress leading to lower motivation and morale of employees to support implementation activities of the techniques used to bring out-productivity such as $5 \mathrm{~S}$ and TPM.

The regression analysis for the model of psychological factors -implementation of $5 \mathrm{~S}$ and TPM refers that the findings support the second hypothesis. Therefore, this hypothesis was accepted.

Hypothesis 2: Psychological factors would have a strong role in implementation of $5 S$ and TPM. 


\subsubsection{Multiple Regression for Ethical and Psychological Factors with Implementation of 5S and TPM}

The multiple regression analysis has also been performed for the two main variables of the current study: ethical and psychological factors and the implementation of 5S and TPM. This regression was performed to make sure which variable is most influential in the implementation of $5 \mathrm{~S}$ and TPM in the three factories under study as well as to test the third hypothesis (Hypothesis 3: Ethical factors would have a bigger role in $5 \mathrm{~S}$ and TPM implementation than psychological factors). The results of this regression are shown in Table 10.

\begin{tabular}{|c|r|r|r|r|r|r|r|r|}
\hline Model & \multicolumn{1}{c|}{$\mathbf{R}$} & \multicolumn{1}{c|}{$\mathbf{R}^{2}$} & \multicolumn{1}{|c|}{ Adj. $\mathbf{R}^{2}$} & \multicolumn{1}{c|}{$\mathbf{F}$} & \multicolumn{1}{c|}{ Sig. } & \multicolumn{1}{c|}{ Beta } & \multicolumn{1}{c|}{$\mathbf{~}$} & \multicolumn{1}{c|}{ Sig. } \\
\hline & .559 & .312 & .306 & 53.291 & .000 & & & \\
\hline Ethical factors & & & & & & .276 & 5.706 & .000 \\
\hline Psychological factors & & & & & & .242 & 4.102 & .000 \\
\hline
\end{tabular}

Predictors: (Constant), psychological factors, ethical factors

Dependent variable: Implementation of $5 \mathrm{~S}$ and TPM

Table 10. Multiple simultaneous regression analysis for ethical and psychological factors - implementation of 5S and TPM

The multiple regression findings of this study refer that the value of $\mathrm{R}$ here is 0.559 . This value shows that the two independent variables of ethical factors and psychological factors have a strong relationship with implementation of $5 \mathrm{~S}$ and TPM. The results indicate that the value of $\mathrm{R}$ Square here is 0.312 . This means that the two independent variables of ethical factors and psychological factors cause $31.2 \%$ variation in the implementation of 5S and TPM. However, the ethical factors have a greater role $(\beta=$ $0.276, \mathrm{p}<0.05)$ in the implementation of $5 \mathrm{~S}$ and TPM, compared to the role of psychological factors $(\beta$ $=0.242, \mathrm{p}<0.05)$ in the present study. It means that the ethical factors would have a greater positive influence of $27.6 \%$ on the implementation of $5 \mathrm{~S}$ and TPM compared to the impact of psychological factors, which reached $(24.2 \%)$. Hence, these results support the third hypothesis.

\section{Hypothesis 3: Ethical factors would have a bigger role in $5 S$ and TPM implementation than psychological factors.}

Thus, the employee related factors such as ethical and psychological represent the concerns of the employees regarding the modern techniques such as $5 \mathrm{~S}$ and TPM, which could either raise or lower the employees' morale and motivation necessary for the successful implementation of these techniques. These factors as highlighted by the results of the present study and the previous studies indicate that the management should focus on mitigating the apprehensions employees face regarding the implementation of these modern techniques. These apprehensions should be addressed before any implementation task is 
taken up, and employees should be a sufficiently apprised of the techniques beforehand. Only when employees are fully on board and aligned with the management should the implementation be started. As well, many problems of implementation of 5S and TPM faced by the selected cement factories have been due to the fact that employees were not made fully aware of these techniques and their benefits for them before the start of the implementation.

\section{Crucial Differences between the Current Study and Previous Studies}

The key aim of this study is to investigate the role of ethical and psychological factors in the implementation of 5S. Through this objective, It can observe that the current study focused on studying the different set of factors represented in (ethical and psychological), which would have an active role in influencing the performance of employees negatively or positively before and during the implementation of $5 \mathrm{~S}$ and TPM in the organization. This is contrary to what was done many of previous studies such as (Ahuja \& Khamba, 2008b; Hegde et al., 2009; Arashpour et al., 2009; Graisa \& Al-Habaibeh, 2011; Panneerselvam, 2012; Haddad \& Jaaron, 2012; Singh et al., 2013; Poduval \& Pramod, 2015) in the area of 5S and TPM. Where these studies have focused on studying the other factors such as (organizational, technological, operational and others), which have an effective role in during implementing $5 \mathrm{~S}$ and TPM only. This without realizing the fact that it is also necessary to examine other factors such as (ethical and psychological) that would affect the capabilities and employee morale before and during the implementation of those techniques (5S and TPM) that are used to bring out the best productivity.

\section{Conclusion}

5S and Total Productive Maintenance (TPM) are recognized as key concepts in Lean and World Class Manufacturing models. Nevertheless, few organizations understand the benefits that can accrue from their simultaneous implementation. Where, several previous studies highlighted that simultaneous implementation of these two techniques (5S and TPM) is not impossible, and their implementation together in a single system can bring many benefits to the industrial organizations, including a large improvement the safety at the work environment, asset performance, quality, productivity and most importantly financial performance. All these, in turn, will help these organizations to improve the current situation and to strengthen its competitive position by improving the production effectiveness and meeting the needs of customers and consumers as required.

However, the successful implementation of $5 \mathrm{~S}$ and TPM depends not only on the diagnosis of the obstacles and challenges such as (organizational, administrative, operational, technological and financial) 
that hinder the implementation of these techniques (5S and TPM) to improve the overall production lines effectiveness and attain competitive advantage, but it also depends on the capacities of human resources (employees) that affect the successful implementation of $5 \mathrm{~S}$ and TPM in the organization. Thus, the employee is a considered the main and decisive component for successful implementation of $5 \mathrm{~S}$ and TPM and achieving the desired competitive advantage for organizations. Therefore, it was very necessary to highlight by the current study on this component (employee) through a set of ethical and psychological factors and their role in the implementation of the tasks of $5 \mathrm{~S}$ and TPM.

Given the importance of the above, the main objective of the current research came to get better understand the role of ethical and psychological factors in the implementation of $5 \mathrm{~S}$ and TPM. The results showed that the successful implementation of these techniques (5S and TPM) by the industrial organizations to improve the production lines effectiveness and attain the desired competitive advantage depends also depends on a set of ethical and psychological factors addressed by the present study, which in turn affecting the performance of employees and thereby on the proper implementation of $5 \mathrm{~S}$ and TPM and difference in their implementation levels.

Therefore, organizations, including the factories under study (Tasluja, Mass and Bazian) should uphold these ethical and psychological aspects and work to addressed and enhance them continuously if they aspire to improve the level of implementation of $5 \mathrm{~S}$ and TPM to improve the production lines effectiveness to the fullest extent possible. This is by: 1) providing the necessary support financially and morally for employees. 2) Providing the necessary empowerment and autonomy for employees in the implementation of tasks. 3) Providing the necessary training programs and correct to improve the capacity and potential of the employees to perform the tasks of these techniques (5S and TPM) as required. 4) Creating a climate of trust and cooperation between the organization management and employees alike. 5) Providing a safe and comfortable working environment. 6) Enhancing awareness and sense of responsibility for employees by educating them of the importance of the implementation of such techniques (5S and TPM), and what are the benefits to be derived from their implementation for employees and factory alike as well as by involving them (especially the skilled employees) in the process of take decisions related to proper implementation of these techniques. All this will enhance the capabilities of organizations for the proper implementation of these techniques and on time. 


\section{References}

Ahuja, I.P.S., \& Khamba, J.S. (2008a). Total Productive Maintenance: Literature Review and Directions. International Journal of Quality and Reliability Management, 25(7), 709-756.

https://doi.org/10.1108/02656710810890890

Ahuja, I.P.S., \& Khamba, J.S. (2008b). Strategies and Success Factors for Overcoming Challenges in TPM Implementation in Indian Manufacturing Industry. Journal of Quality in Maintenance Engineering, 14(2), 123-147. https://doi.org/10.1108/13552510810877647

Ananthanarayanan, K.R.M. (2006). Application of 5S Management System in NDE Laboratory. In National Seminar on Non-Destructive Evaluation, 7-9 December, 2006.

Ansari, A., \& Modarress, B. (1997). World-class strategies for safety: a Boeing approach. International Journal of Operations \& Production Management, 17(4), 389-398. https://doi.org/10.1108/01443579710159978

Arashpour, M.R., Enaghani, M.R., \& Karimi, M. (2009). The Relationship between Lean and TPM (Master's thesis, University of Borås, Borås, Sweden). Available online at: http://bada.hb.se/bitstream/2320/5630/1/Arashpour,\%20Enaghani,Karimi.pdf

Aspinwall, E., \& Elgharib, M. (2013). TPM Implementation in Large and Medium Size Organisations. Journal of Manufacturing Technology Management, 24(5), 688-710. https://doi.org/10.1108/17410381311327972

Attri, R., Grover, S., Dev, N., \& Kumar, D. (2013). An ISM approach for modelling the enablers in the implementation of Total Productive Maintenance (TPM). International Journal of System Assurance Engineering and Management, 4(4), 313-326. https://doi.org/10.1007/s13198-012-0088-7

Bayo-Moriones, A., Bello-Pintado, A., \& Merino-Díaz de Cerio, J. (2010). 5S Use in Manufacturing Plants: Contextual Factors and Impact on Operating Performance. International Journal of Quality and Reliability Management, 27(2), 217-230. https://doi.org/10.1108/02656711011014320

Becker, S., Bryman, A., \& Ferguson, H. (2012). Understanding research for social policy and social work: themes, methods and approaches. Chicago, USA: The Policy Press.

Boca, G.D. (2011). Kaizen Methodology in Quality Management to Reduce Wastes. Studia Universitatis Vasile Goldiș, Arad-Seria Ștïnţe Economice, 21(1), 375-381.

Bonavia, T., \& Marin-Garcia, J.A. (2011). Integrating Human Resource Management into Lean Production and their Impact on Organizational Performance. International Journal of Manpower, 32(8), 923-938. https://doi.org/10.1108/01437721111181679

Brah, S.A., \& Chong, W.K. (2004). Relationship Between Total Productive Maintenance and Performance. International Journal of Production Research, 42(12), 2383-2401. https://doi.org/10.1080/00207540410001661418 
Chan, F.T.S., Lau, H.C.W., Ip, R.W.L., Chan, H.K., \& Kong, S. (2005). Implementation of Total Productive Maintenance: A Case Study. International Journal of Production Economics, 95(1), 71-94. https://doi.org/10.1016/j.ijpe.2003.10.021

Cohen, S., \& Eimicke, W. (2003). The effective public manager: Achieving success in a changing government. San Francisco, USA: John Wiley \& Sons.

Cua, K.O., McKone-Sweet, K.E., \& Schroeder, R.G. (2006). Improving performance through an integrated manufacturing program. The Quality Management Journal, 13(3), 45-60.

Da Silveira, G.J.C. (2006). Effects of Simplicity and Discipline on Operational Flexibility: an Empirical Reexamination of the Rigid Flexibility Model. Journal of Operations Management, 24(6), 932-947. https://doi.org/10.1016/j.jom.2005.11.004

Dennis, P. (2016). Lean Production simplified: A plain-language guide to the world's most powerful production system. CRC Press, Taylor \& Francis Group.

Dhindsa, J.S. (2012). The Effects Of Lean Intervention (5S) On Perceived Musculoskeletal Workload And Perceived Hazardous Working Conditions In A Health Center Pharmacy. Working paper. University of Pune, India.

Esain, A., Williams, S., \& Massey, L. (2008). Combining planned and emergent change in a healthcare lean transformation. Public Money and Management, 28(1), 21-26.

Eswaramoorthi, M., Kathiresan, G.R., Prasad, P.S.S., \& Mohanram, P.V. (2011). A survey on lean practices in Indian machine tool industries. The International Journal of Advanced Manufacturing Technology, 52(9-12), 1091-1101. https://doi.org/10.1007/s00170-010-2788-y

Eti, M.C., Ogaji, S.O.T., \& Probert, S.D. (2006). Development and Implementation of Preventive-Maintenance Practices in Nigerian Industries. Applied Energy, 83(10), 1163-1179. https://doi.org/10.1016/j.apenergy.2006.01.001

Gajdzik, B. (2009). Introduction of Total Productive Maintenance in Steelworks Plants. Metalurgija, 48(2), 137-140.

Gapp, R., Fisher, R., \& Kobayashi, K. (2008). Implementing 5S within a Japanese Context: An Integrated Management System. Management Decision, 46(4), 565-579. https://doi.org/10.1108/00251740810865067

Ginbey, A. (2013). Reducing HiSeq Setup Times in Genomic Services Laboratory with 5S: Implications for Productivity and Quality. Working paper. California State University, San Marcos.

Ginder, A., Robinson, A., \& Robinson, C.J. (1995). Implementing TPM: The North American Experience. USA: Productivity Press. 
Graham, J.W. (1986). Principled organizational dissent: A theoretical essay. Research in organizational behavior, $8,1-52$.

Graisa, M., \& Al-Habaibeh, A. (2011). An investigation into current production challenges facing the Libyan cement industry and the need for innovative total productive maintenance (TPM) strategy. Journal of Manufacturing Technology Management, 22(4), 541-558. https://doi.org/10.1108/17410381111126445

Haddad, T.H., \& Jaaron, A.A. (2012). The Applicability of Total Productive Maintenance for Healthcare Facilities: An Implementation Methodology. International Journal of Business, Humanities and Technology, 2(2), 148-155.

Haroun, A.E., \& Duffuaa, S.O. (2009). Maintenance Organization. In Handbook of Maintenance Management and Engineering (pp. 3-15). London: Springer. https://doi.org/10.1007/978-1-84882-472-0_1

Hayes, R.H., \& Pisano, G.P. (1994). Beyond world-class: the new manufacturing strategy. Harvard business revien, $72(1), 77-86$.

Hegde, H.G., Mahesh, N.S., \& Doss, K. (2009). Overall Equipment Effectiveness Improvement by TPM and 5S Techniques in a CNC Machine Shop. SaSTech, 8(2), 25-32.

Ho, S.K., \& Cicmil, S. (1996). Japanese 5-S Practice. The TQM Magazint, 8(1), 45-53. https://doi.org/10.1108/09544789610107261

Hutchins, C.B. (2007). Five "S" Improvement System: An Assessment of Employee Attitudes and Productivity Improvements. USA: ProQuest.

Idris, T. (2001). Entrance Modern in the Administration. College of Management and Economics. Iraq: University House for Publication and Distribution, University of Baghdad.

Ireland, F., \& Dale, B.G. (2001). A Study of Total Productive Maintenance Implementation. Journal of Quality in Maintenance Engineering, 7(3), 183-192. https://doi.org/10.1108/13552510110404495

Jadhav, J.R., Mantha, S.S., \& Rane, S.B. (2014). Exploring Barriers in Lean Implementation. International Journal of Lean Six Sigma, 5(2), 122-148. https://doi.org/10.1108/IJLSS-12-2012-0014

Jain, A., Bhatti, R., Deep, H.S., \& Sharma, S.K. (2012). Implementation of TPM for Enhancing OEE of Small Scale Industry. International Journal of IT, Engineering and Applied SciencesResearch, 1(1), 125-136.

Karim, A., \& Arif-Uz-Zaman, K. (2013). A methodology for effective implementation of lean strategies and its performance evaluation in manufacturing organizations. Business Process Management Journal, 19(1), 169-196. https://doi.org/10.1108/14637151311294912

Kennedy, R., \& Mazza, L. (2010). 5 S and TPM: Working Together as One in TPM3. CTPM. Australasia. 
Khamis, N., Abrahman, M.N., Jamaludin, K.R., Ismail, A.R., Ghani, J.A., \& Zulkifli, R. (2009). Development of 5S Practice Checklist for Manufacturing Industry. In Proceedings of the World Congress on Engineering, London, U.K. 978-988.

Kholopane, P. (2016). The Effect of the Implementation of Six Sigma in Reducing Obsolete Stock and Controlling Stock Inventory at a Flavor Manufacturing Company: A Case Study. In Proceedings of the International MultiConference of Engineers and Computer Scientists (Vol. 2).

Krejcie, R.V., \& Morgan, D.W. (1970). Determining Sample Size for Research Activities. Educational and Psychological Measurements, 30, 607-610. https://doi.org/10.1177/001316447003000308

Kumar, M. (2007). Critical Success Factors and Hurdles to Six Sigma Implementation: The Case of a UK Manufacturing SME. International Journal of Six Sigma and Competitive Advantage, 3(4), 333-351. https://doi.org/10.1504/IJSSCA.2007.017176

Kumar, J., Soni, V.K., \& Agnihotri, G. (2014). Impact of TPM Implementation on Indian Manufacturing Industry. International Journal of Productivity and Performance Management, 63(1), 44-56. https://doi.org/10.1108/IJPPM-06-2012-0051

Lemma, E. (2008). Implementation of TPM (Total Productive Maintenance) in Ethiopian Textile Industries. Doctoral dissertation. Addis Ababa University.

McKone, K.E., Schroeder, R.G., \& Cua, K.O. (2001). The Impact of Total Productive Maintenance Practices on Manufacturing Performance. Journal of Operations Management, 19(1), 39-58. https://doi.org/10.1016/S0272-6963(00)00030-9

Michalska, J., \& Szewieczek, D. (2007). The 5S Methodology as a Tool for Improving the Organization. Journal of Achievements in Materials and Manufacturing Engineering, 24(2), 211-214.

Moradi, M., Abdollahzadeh, M.R., \& Vakili, A. (2011). Effects of Implementing 5S on Total Productive Maintenance: A Case in Iran. Proceedings of the IEEE ICQR. https://doi.org/10.1109/ICQR.2011.6031678

Moulding, E. (2010). 5S: A Visual Control System for the Workplace. UK: Author House.

Mullins, L.J. (2007). Management and Organisational Behaviour. England: Pearson Education.

Nachiappan, R.M., \& Anantharaman, N. (2006). Evaluation of Overall Line Effectiveness (OLE) in a Continuous Product Line Manufacturing System. Journal of Manufacturing Technology Management, 17(7), 987-1008. https://doi.org/10.1108/17410380610688278

Nahm, A.Y., Lauver, K.J., \& Keyes, J.P. (2012). The Role of Workers' Trust and Perceived Benefits in Lean Implementation Success. International Journal of Business Excellence, 5(5), 463-484. https://doi.org/10.1504/IJBEX.2012.048798 
Nelson-Raja, P., Kannan, S.M., \& Jeyabalan, V. (2010). Overall Line Effectiveness-A Performance Evaluation Index of a Manufacturing System. International Journal of Productivity and Quality Management, 5(1), 38-59. https://doi.org/10.1504/IJPQM.2010.029508

Ngugi, K. (2015). Total productive maintenance practices and equipment effectiveness: a case study of Bamburi cement limited. Doctoral dissertation. University of Nairobi.

Panneerselvam, R. (2012). Production and operations management. New Delhi, India: PHI Learning Pvt. Ltd.

Paropate, R.V., Jachak, S.R., \& Hatwalne, P.A. (2011). Implementing approach of total productive maintenance in Indian industries \& theoretical aspect: An overview. Ijaest-International Journal of Advanced Engineering Sciences and Technologies, 1(6), 270-279.

Poduval, P.S., \& Pramod, V.R. (2015). Interpretive structural modeling (ISM) and its application in analyzing factors inhibiting implementation of total productive maintenance (TPM). International Journal of Quality \& Reliability Management, 32(3), 308-331. https://doi.org/10.1108/IJQRM-06-2013-0090

Pramod.V.R. (2007). MQFD: A Model for Synergizing TPM and QFD. Graduate thesis. Cochin University of Science and Technology.

Rahman, M.N.A., Khamis, N.K., Zain, R.M., Deros, B.M., \& Mahmood, W.H.W. (2010). Implementation of 5S practices in the manufacturing companies: A case study. American Journal of Applied Sciences, 7(8), 1182-1189. https://doi.org/10.3844/ajassp.2010.1182.1189

Ramayah, T., Jantan, M., \& Hassan, M.M. (2002). Change management and implementation of Total Productive Maintenance: An exploratory study of Malaysian manufacturing companies. Utara Management Revien, 3(1), 1-17.

Rolfsen, M. (2014). A blueprint paradox: Successful but unintended cross-national translation of total productive maintenance. Journal of Quality in Maintenance Engineering, 20(4), 402-414. https://doi.org/10.1108/JQME-07-2012-0024

Rolfsen, M., \& Langeland, C. (2012). Successful maintenance practice through team autonomy. Employee Relations, 34(3), 306-321. https://doi.org/10.1108/01425451211217725

Roziana, A.N. (2011). 5S Implementation And People Involvement At Muehlbaeur Technologies Sdn. Bhd. Thesis. Universiti Teknikal Malaysia Melaka.

Sahu, H., Batham, J.M., \& Bangar, A. (2012). Implementating Total Productive Maintance In Jamna Auto Industry Malanpur. International Journal of Engineering Research and Technology, 1(9), 1-5.

Sekaran, U., \& Bougie, R.J. (2016). Research methods for business: A skill building approach. UK: John Wiley \& Sons Ltd. 
Seth, D., \& Tripathi, D. (2005). Relationship between TQM and TPM implementation factors and business performance of manufacturing industry in Indian context. International Journal of Quality \& Reliability Management, 22 (3), 256-277. https://doi.org/10.1108/02656710510582480

Singh, R., Gohil, A.M., Shah, D.B., \& Desai, S. (2013). Total productive maintenance (TPM) implementation in a machine shop: A case study. Procedia Engineering, 51, 592-599. https://doi.org/10.1016/j.proeng.2013.01.084

Sousa, R., \& Voss, C.A. (2008). Contingency research in operations management practices. Journal of Operations Management, 26(6), 697-713. https://doi.org/10.1016/j.jom.2008.06.001

Suzuki, T. (1994). TPM in process industries. New York, USA: Productivity Press.

Trevino, L.K., \& Nelson, K.A. (2010). Managing business ethics. USA: John Wiley \& Sons.

Ulrich, D., Zenger, J., \& Smallwood, N. (2013). Results-based leadership. USA: Harvard Business Press.

Van Patten, J. (2006). A second look at 5S. Quality progress, 39(10), 55-59.

Venkatesh, J. (2007). An introduction to total productive maintenance (TPM). Available at: http://www.plant maintenance.com/articles/tpm intro.shtml/ (Accessed: December 2016).

Wagel, W.H. (1990). On The Horizon: Human Resources. New York, USA: Force press.

Warwood, S.J., \& Knowles, G. (2004). An investigation into Japanese 5-S practice in UK industry. The TQM Magazine, 16(5), 347-353. https://doi.org/10.1108/09544780410551287

Westphal, J.D., Gulati, R., \& Shortell, S.M. (1997). Customization or conformity? An institutional and network perspective on the content and consequences of TQM adoption. Administrative Science Quarterly, 42(2), 366-394. https://doi.org/10.2307/2393924

Journal of Industrial Engineering and Management, 2017 (www.jiem.org)

Article's contents are provided on an Attribution-Non Commercial 3.0 Creative commons license. Readers are allowed to copy, distribute and communicate article's contents, provided the author's and Journal of Industrial Engineering and Management's names are included. It must not be used for commercial purposes. To see the complete license contents, please visit http://creativecommons.org/licenses/by-nc/3.0/. 